\title{
EVOLUCIÓN Y FUTURO DEL DERECHO DEL TRABAJO
}

\section{Ricardo Francisco Seco²}

Sumario: I.- La cuestión social del siglo XIX. II.-La irrupción del Derecho del Trabajo en la historia. 1.-Sus inicios. 2.-El Derecho del Trabajo clásico. III.- La crisis petrolera y sus consecuencias. 1.-La crisis petrolera. 2.-Flexibilización como precarización. IV.- La nueva cuestión social. V.-Crisis del Derecho del Trabajo. VI.-Ensayo de una posible respuesta.

Resumen: La cuestión social es el cuadro de las condiciones de vida y trabajo de los trabajadores, consecuencia de la Revolución Industrial en Europa. El Derecho del Trabajo constituyó una reacción contra la injusticia. Desde 1973-75 en adelante se produjo una modificación objetiva de las condiciones de trabajo de las personas en el mundo. Advino la flexibilización laboral. Flexibilización puede usarse como "sinónimo de desregulación y precarización del contrato de trabajo. El último cuarto del siglo XX en adelante se caracteriza por la creciente pobreza estructural, el desempleo y la exclusión y el problema de la inseguridad. El Derecho del Trabajo ya no será el que fue. Deberá reinventarse sin perder lo que lo identifica: su función de protección de los hiposuficientes. Debe procurar que el trabajo humano no se convierta en una mercancía. Se debe pensar el futuro del Derecho del Trabajo, pero sin olvidar sus raíces.

Palabras clave: Conflicto. Crisis. Flexibilización. Mercancía. Protección.

\section{I.- La cuestión social del siglo XIX}

Ella es conceptualizada como el cuadro de condiciones de vida y de trabajo de los trabajadores resultantes del proceso de industrialización principalmente en Europa y América del Norte. Ante las condiciones sociales imperantes resultaba inaplazable que se encararan "medidas para corregir abusos y promover propuestas para el mejoramiento de la situación de los obreros o, en términos que por entonces se consideraban equivalentes, de los pobres". 3

\footnotetext{
1 *Aclaración inicial: Este artículo es el producto de una exposición realizada en una reunión plenaria de la Sala de Derecho Laboral y Derecho Procesal Laboral de la UBP en 2019. Posteriormente su contenido esencial fue publicado en AA.VV., Nuevas tecnologías. Presente y futuro del derecho del trabajo, ARESE, César(director), CHÉRCOLES, Ricardo León- FERRARIO, María de los Ángeles (coordinadores), Rubinzal Culzoni, Santa Fe, 2019, p.59, todo ello antes de la pandemia del Covid-19.

En esta revista digital se ha preferido dejarlo sin agregado alguno en razón de que ya varios artículos de esta revista se ocupan de las consecuencias del Covid-19 en el Derecho del Trabajo argentino y es suficiente.

2 Abogado y notario(UCC), doctor en Derecho y Ciencias Sociales(UNC), profesor de grado de DTySS (UCC y UBP), profesor de posgrado de varias universidades argentinas y una extranjera, Presidente de la Sala de DL y DPL del Instituto de Investigaciones Jurídicas de la Universidad Blas Pascal de Córdoba, Secretario General de la AADTYSS-Córdoba, exvocal de la Cámara Civil y Comercial, Trabajo y Familia, Cruz del Eje, Córdoba, publicista. E-mail de contacto: ricardoseco58@gmail.com.

3 BARBAGELATA, Héctor-Hugo, Curso sobre la evolución del pensamiento juslaboralista, Fundación de Cultura Universitaria, Montevideo, 2009 , p.18.
} 
Con el advenimiento de la empresa capitalista, consecuencia del liberalismo político que sostenía la libertad contractual y la concepción robusta de la propiedad privada, se produjo la separación tajante entre los propietarios del capital y los aportantes del trabajo bajo el régimen del salariado. ${ }^{4}$

Ya no estaban reunidos en una persona el propietario de la materia prima y el de la máquina- aunque ella fuera muy elemental- usada para transformarla y quien aportaba la actividad humana transformadora. En esa época se dieron inventos como la máquina de vapor, el ferrocarril, los buques de vapor, el motor eléctrico, el motor a explosión, el cemento armado, la dínamo, la máquina frigorífica, el horno eléctrico, el teléfono, etcétera. ${ }^{5}$

Los trabajadores realizaban jornadas extensas; mujeres y niños trabajaban en tareas insalubres y en condiciones inhumanas; había hacinamiento en viviendas, entre otras condiciones de vida. En ese tiempo apareció una nueva clase social: el proletariado, que se sentó en las urbes, generando nuevos pobres. Era menester la protección de esas personas. ${ }^{6}$

La Cuestión Social fue efecto o consecuencia de la "Revolución Industrial"7- ahora se dice que aquélla fue la primera-·y planteó un peculiar problema de justicia.

\section{II.-La irrupción del Derecho del Trabajo en la historia}

\section{1.-Sus inicios}

El Derecho del Trabajo "constituyó una reacción contra la injusticia que, en la práctica, significó dejar librada la relación del trabajo a la concepción individualista del derecho civil, que niega la existencia de derechos fundamentales, aunque ello haya sido motivo de un acuerdo."

Para ello adoptó diversas técnicas. ${ }^{8}$ Reaccionó ante la disparidad negocial, ante el trabajo humano reducido a mercancía que se vende de acuerdo a las condiciones de mercado, con prescindencia del valor intrínseco.

Surgió como un derecho típicamente protector de la clase trabajadora, que se encontraba afectada "no sólo por la ambición desmedida del capital sino también por el frío e inmutable principio de la autonomía de la voluntad, que proclamaba el Derecho Civil, como base y esencia de toda relación contractual." 9

La legislación estatal empezó a utilizar diversas herramientas como la "reducción de la capacidad de mando empresario (del empleador que se consideraba dueño exclusivo de la misma por el hecho de que era de los bienes de producción y por lo tanto podía de hecho imponer las condiciones de trabajo), reconocimiento de las autonomías colectivas, tratamiento privilegiado del poder de negociación colectivo, contralor administrativo, lo que llevó a la limitación de las facultades jerárquicas del empleador."10

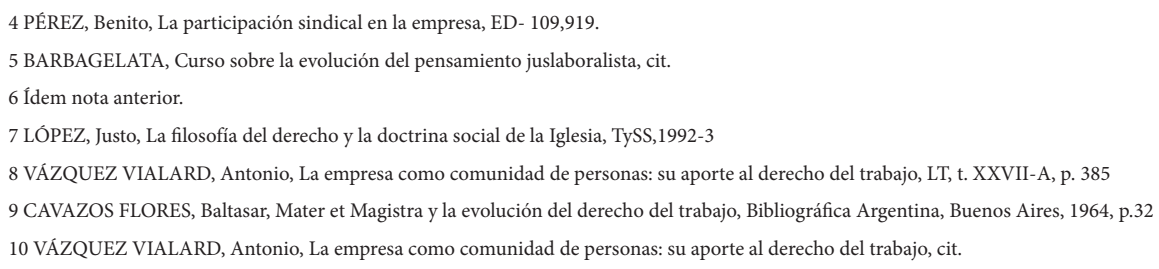


Esas técnicas se enderezaron a equilibrar jurídicamente lo que era un desequilibrio económico inicial. Se sancionaron normas mínimas de cumplimiento obligatorio que alteraron la autonomía de la voluntad, que funcionan por sobre o por debajo de las condiciones establecidas. Las reglas se adecuaron al principio de protección del trabajador que dio lugar a la aparición de un derecho nuevo. ${ }^{11}$

\section{2.-El Derecho del Trabajo clásico}

Éste se expresó en una época que se caracterizó por una distinta forma de coordinación interempresarial, la que se basaba, en especial, en un proceso constante, en serie, según el modelo taylorista - fordista, con un empleo subordinado, estable y a tiempo completo, en una empresa de coordinación vertical y horizontal y gigantesca.

La principal particularidad del Derecho del Trabajo se relaciona "con el objeto de su protección y supone una nueva actitud ante las realidades del mundo del trabajo. Implica un cambio en la forma de concebir la igualdad de las personas las que, como señalaba Radbruch' deja de ser así, punto de partida del Derecho, para convertirse en meta o aspiración del orden jurídico."'12

Nuestro Derecho "no es un derecho de esencia sino de existencia por lo cual el amparo preferente al trabajador es el principio rector de toda la disciplina y su significación y consecuencias han motivado valiosísimos aportes." ${ }^{\text {13 }}$

El Derecho del Trabajo así configurado constituyó el "medio más eficaz de aplicación de los principios de justicia social que se encuentran consignados en las legislaciones laborales." ${ }^{14}$

Es él una aplicación constitucional, y luego legal, del antiguo principio romano "favor debilis" indicado por el papa León XIII en su encíclica Rerum novarum de 1891, n²5, cuando se refiere a la preferente atención del Estado a los proletarios, carta que es una de las fuentes originarias del nuevo derecho, como la define el papa Pío XI en la encíclica Quadragésimo anno, 28, de 1931.

En él se encuentran normas de orden público relativo o de protección y los principios que lo informan, entre ellos el de irrenunciabilidad, interesan a la colectividad que su cumplimiento sea coactivo.

El principio protector-que en Argentina tiene sede en el art.14 bis de la Constitución Nacional- si bien se dirige primordialmente al legislador, su cumplimiento "atañe asimismo a los restantes poderes públicos, los cuales, dentro de la órbita de sus respectivas competencias, deben hacer prevalecer el espíritu protector que anima a dicho precepto". ${ }^{15}$

Es él la base y fundamento del Derecho del Trabajo.

\footnotetext{
11 VÁZQUEZ VIALARD, “Ayer, hoy y mañana en el derecho del trabajo”, Rev. Relaciones Laborales y Seguridad Social Nº1, 1995, p. 64/65

12 BARBAGELATA, Héctor-Hugo, El particularismo del Derecho del Trabajo y los derechos humanos laborales, Fundación de Cultura Universitaria, $2^{\text {a }}$ edición, Montevideo, 2009, p.20

13 Ídem nota anterior.

14 CAVAZOS FLORES, ob.cit

15 Corte Suprema de Justicia de la Nación, 14/9/2004, "Vizzoti, Carlos Alberto c/Amsa S.A. s/Despido", RDL, Número extraordinario, Fallos recientes de la Corte Suprema de Justicia de la Nación, Rubinzal Culzoni, Santa Fe, 2004, p.7..
} 
Este derecho "se caracteriza por la novedad de haber descubierto, primero, al trabajador como persona". ${ }^{16}$ Su objeto es la regulación del trabajo dependiente. Mantiene la característica más específica del trabajo asalariado "que reside desde el punto de vista jurídico en el menoscabo de la libertad individual que entraña forzosamente. El objeto propio del derecho del trabajo asalariado es poner límites a ese menoscabo: por una parte restituir las atribuciones del empleador a lo estrictamente necesario para la ejecución del contrato laboral; por otra parte restituyendo a los trabajadores en un plano colectivo las libertades que pierden en el plano personal (derecho a la afiliación sindical, a la negociación colectiva, a la huelga)." Empero "Ios planteamientos generales del Derecho del Trabajo no han perdido un ápice de validez. Habrá que adaptarlos de manera continua al cambio socioeconómico sin dejar de referirlas a los valores que constituyen sus cimientos."17

La función del Derecho del Trabajo es "ajustar la relación que se da entre por lo menos dos personas vinculadas por el hecho laboral. Éste consiste en la prestación por una parte y consecuente recepción por la otra de trabajo humano, que esta última dirige y remunera." "El derecho establece el marco jurídico con el objeto de facilitar el despliegue armónico de la relación que se da dentro de un contexto social que se caracteriza por un desigual poder de negociación de las partes, de modo que no entorpezca el desarrollo de las personas involucradas." ${ }^{18}$

En el Derecho del Trabajo hay, además, otras notas que hacen a su particularismo:

a) Subyacencia del conflicto en las relaciones laborales. b) Dimensión colectiva del conflicto laboral. c) Papel central de la negociación. d) Repercusiones en el plano de las fuentes del derecho. e) Significación del tiempo social en el sistema normativo-laboral. f) Variedad y poderes de los operadores jurídicos. ${ }^{19}$

En los inicios del Derecho del Trabajo- a fines del siglo XIX y principios del siglo XX- la acción requerida ante la clara desproporción entre el aporte del trabajador y su retribución imponía la adopción de medidas concretas a fin de asegurar mínimos (en cuanto se refiere a salarios, condiciones de trabajo), que le permitieran a una gran parte de la población, desarrollar su existencia en condiciones compatibles con la dignidad humana. De ese modo, paulatinamente, se fueron mejorando las condiciones del trato dentro -lo que es fundamental en el derecho-, de lo que hay para repartir (aunque no siempre se hace con justicia).

De acuerdo con esa concepción y en función de la realidad socio-económica, se tuvo en cuenta el esquema que presentaba el sistema productivo prevalente en los países en que se desarrollaba ese derecho "emergente", nuevo.

Si bien en ellos el proceso industrial no era el único a través del cual se elaboraba la renta social (parte importante de esto, se lograba en el ámbito de la producción primaria y en la terciaria), sin embargo, en razón de su mayor dinamismo (a punto tal que se denomina a esa etapa histórica como la de la sociedad industrial), se tomó en cuenta lo que ocurría con motivo de ese proceso. Éste, en especial, fue influenciado por dos criterios que tuvie-

16 LÓPEZ, Justo, La filosofía del derecho y la doctrina social de la Iglesia, TySS,1992-3.

17 SUPIOT, Alain, "Introducción a las reflexiones sobre el trabajo", Revista Internacional de Trabajo, vol.115 (1996) núm.6, Número Especial, Reflexiones cruzadas sobre el trabajo y su porvenir, Organización Internacional del Trabajo, Ginebra

18 VÁZQUEZ VIALARD, Ayer, hoy y mañana en el derecho del trabajo, cit

19 BARBAGELATA, El particularismo del Derecho del Trabajo y los derechos humanos laborales, cit., p.20. 
ron amplia repercusión: el fordismo y el taylorismo que, en cierta manera, determinaron las líneas fundamentales del proceso de producción en el sector secundario. ${ }^{20}$

En consecuencia, se tomó como modelo la relación que se daba en la industria que, por lo común, lo era la gran empresa, en que la fábrica constituía el centro de producción. Fue en base a ese esquema que se delinearon las figuras del empleador y del trabajador. Ello se expresó en un presupuesto fundamental: la uniformidad del estatuto del trabajador "en relación de dependencia" al servicio de un empresario, que lo hace junto con otros que tienen intereses comunes, de donde surge una cierta solidaridad, ya que laboraban en un mismo espacio físico.

La fábrica constituía el centro de producción de bienes respecto de la que el empresario adoptaba la decisión sobre el qué y el cómo producir, con vistas a optimizar su inversión; él controlaba el proceso del trabajo y coordinaba las prestaciones laborales. En ella se consolidaban las prácticas de uniformidad de las condiciones de trabajo. En el taller industrial trabajan varias personas utilizando máquinas, al principio muy rudimentarias, lo que facilitó un mayor contacto con los compañeros que realizan la tarea en el mismo local. Esto facilitó la cohesión social que explica gran parte del desarrollo de las acciones promovidas como consecuencia del fenómeno sindical. ${ }^{21}$

Una de las importantes herramientas que utilizó el Derecho del Trabajo como medio para privilegiar el poder de negociación colectiva de los trabajadores fue el sindicato fruto de la cohesión sociocultural, de la que nació un criterio de solidaridad que se desarrolló a fin de disminuir los efectos de la explotación económica y de la exclusión social, a cuyo efecto se destacó el valor de lo colectivo. Ello llevó a que la normativa tendiera a adoptar una cierta uniformidad, no obstante que debía ser aplicada respecto de situaciones que admitían apreciables diferencias. La actividad productiva en esa época, se realizaba tomando como modelo las grandes empresas industriales con producción en serie, organizadas en forma centralizada y jerárquica, en la que todos los que trabajaban en ellas, lo hacían a un mismo tiempo, en un mismo lugar, a las órdenes directa de la dirección de la empresa, a ciclo completo y con empleo estable.

Principalmente durante los llamados "30 años gloriosos" (desde 1945 a 1975), el Derecho del Trabajo estuvo diseñado por la norma estatal sobre el modelo del Estado de Bienestar de base nacional.

\section{III.- La crisis petrolera y sus consecuencias}

\section{1.-La crisis petrolera}

Se dio en 1973-1975 y fue multicausal. Trajo graves consecuencias que, entre otros aspectos, se reflejaron en una disminución de la actividad industrial (uno de los importantes motores de la expansión económica) y en el incremento del desempleo. Planteó problemas de orden social respecto de las comunidades que se habían desarrollado en base a una política de pleno empleo. Trajo recesión con su secuela de desocupación. Se desató una carrera por reducir costos, mejorar la competitividad. ${ }^{22}$

20 VÁZQUEZ VIALARD, Ayer, hoy y mañana en el derecho del trabajo, cit.; BARBAGELATA, El particularismo del Derecho del Trabajo y los derechos humanos laborales, cit., p.20.

21 Ídem nota anterior.

22 VÁZQUEZ VIALARD, Ayer, hoy y mañana en el derecho del trabajo, cit. 
Para paliar esa situación se adoptaron una serie de medidas, entre ellas, la de incrementar la competitividad, a fin de que, a través de la exportación, se solucionara la crisis interna.

Desde 1973-75 en adelante se produjo una modificación objetiva de las condiciones de trabajo de las personas en el mundo.

"Algunas modificaciones introducidas al influjo de la experiencia recogida en otros países, entre ellos Japón y otros de Oriente que despertaban a un crecimiento económico, se plasmó en la introducción de nuevos procesos productivos. Estos no se realizaron en la línea de la actividad desplegada en los países líderes de acuerdo con el desarrollo realizado en los siglos XIX y principios del XX. El esquema que éstos habían seguido, en cuanto se refiere a la organización, tendía a establecer un régimen de producción integral en una fábrica grande, de producción en serie de productos homogéneos. Se incubó así lo que se dio en llamar "el fin del fordismo", que marcó los inicios de una transformación del proceso que había asociado producción y productividad, así como consumo y competencia. Se inició una nueva realidad empresarial que se fundamentó en una tarea que se complementa en una organización en red, con procesos de subcontratación que tienen como núcleo central a una gran empresa, que constituye una estructura de telaraña con alianzas estratégicas con los subcontratados, en vez de una fábrica que lo hace todo. Se promovió, así un tipo de economía en redes."23

Surgió el sistema "Toyota" de producción. ${ }^{24}$

La descentralización productiva multiplicó los centros de imputación de cargas y responsabilidades y diversificó los poderes de organización.

Desorganizó la clásica figura del empresario, que ya no controlaba el entero ciclo productivo y la fuerza de trabajo necesaria para producir el bien o prestar el servicio. La figura del empleador se difuminó al perder la transparencia que requiere la seguridad jurídica; se disolvió en una telaraña en la que acreció la fuerza de las empresas situadas en el epicentro, sobre el mercado de trabajo globalizado. El poder de dirección era externo a la empresa; hay una pluralidad organizada de sujetos frente al trabajador. ${ }^{25}$

También ese proceso afectó la figura clásica del trabajador. El derecho del trabajo se desarrolló a través de un presupuesto: la uniformidad del estatuto del trabajador al servicio de un empresario, que lo hacía con otros, con los que tenía intereses comunes, de donde surgía una cierta solidaridad, fruto de trabajar en un mismo espacio físico.

Con el cambio que produjo el proceso de descentralización productiva de la uniformidad normativa se pasó a la diversidad. Ésta fue alimentada por nuevos incentivos (de carácter legislativos, jurisprudenciales y de gestión de "mano de obra") tendiéndose a revivir una forma de relación personalizada (no absorbida por lo colectivo). Se pretendió recuperar para el contrato de trabajo los espacios de autonomía históricamente perdidos y volver a un régimen de individualización que pone a disposición del empleador (empresario, management), mayores márgenes de elasticidad y libertad del trabajo. 
Se produjo la segmentación del proceso productivo. El nuevo proceso estratificó a todos los trabajadores de la empresa-red, en función de la calidad de su empleo. Éste ya no se mide en razón de criterios tradicionales: habilidades profesionales, experiencia o resultados económicos de la empresa. A mayor lejanía del epicentro se degradan las condiciones de trabajo.

Se somete a los trabajadores a una situación de precariedad no sólo salarial, de desempleo, a tasas de siniestralidad laboral, de aumento del trabajo a tiempo parcial, lo que suele ser una consecuencia de la universalización de las nuevas tecnologías informáticas y de la comunicación.

\section{2.-Flexibilización como precarización}

Con la crisis del petróleo advino la flexibilización laboral.

Con ella se buscó recuperar libertades y facilidades para el empleador. Sus defensores usaron el argumento de la eficacia para vencer la rigidez considerando que la norma laboral era un obstáculo, un impedimento para tratar al trabajo como una mercancía sujeta exclusivamente a las leyes del mercado. Flexibilización puede usarse como "sinónimo de desregulación y precarización del contrato de trabajo o, por el contrario, como un proceso de adaptación del sistema de relaciones laborales a los nuevos condicionamientos que impone la realidad." 26

Desregular "alude a una presupuesta sobrecarga normativa que interfiere en el desenvolvimiento de las actividades que regula, entonces se desjuridifican los conflictos dando mayor importancia a las convenciones colectivas sustituyendo ciertas garantías legales por garantías convencionales, a través de la autorregulación entre las partes modificando más que las normas el método normativo". ${ }^{27}$

Para otro puede entenderse por desregular como eliminar la norma protectoria. ${ }^{28}$

Se afirma que es posible flexibilizar sin desregular, como cuando se modifican las garantías dentro del cuerpo normativo, pero que la desregulación aparejará más flexibilidad pues "a través de la autorregulación ambas partes tendrán que ceder en algunos aspectos para beneficiarse en otros." ${ }^{29}$

Precarizar "significa la posibilidad de ocupar mano de obra sin el cumplimiento de ciertas obligaciones normales". 30

Los contratos precarizados se inician fácilmente, se desarrollan sin el cumplimiento de cargas sociales, ni de la jornada laboral, ni de las remuneraciones de convenio normalmente exigidas y finalizan sin indemnización.

Entre los ejemplos de la aplicación de este instrumento se hallan "en materia de despido

26 LIVELLARA, Carlos Alberto, Las relaciones laborales en el inicio del siglo XXI, TySS, 2002-292.

27 MONTORO GIL, Gonzalo Vicente, La flexibilización en las relaciones laborales y el abanico axiológico- doctrinario nacional e internacional (19811998), DT-2000-A,342

28 LIVELLARA, ob.cit.

29 MONTORO GIL, ob.cit..

30 ALTAMIRA GIGENA, Raúl E., "Flexibilidad laboral”, en Anales de las I y II Jornadas Regionales de Actualización y Extensión en Derecho del Trabajo, Cruz del Eje, Alveroni, Córdoba, 1994, p.139. 
(abaratamiento y reducción de los recaudos formales), mayor recepción y uso de los contratos por tiempo determinado y otras formas de temporalidad o de contrataciones atípicas, contratos a tiempo parcial, contratos con finalidad formativa, habilitación de agencias privadas de empleo y de trabajo temporal, predominio de técnicas procedimentales de tutela por sobre las que se basan en normas sustantivas, generalización de las diversas formas de intermediación laboral en procesos de descentralización productiva, flexibilización de la jornada de trabajo y los descansos, introducción de mecanismos de flexibilidad interna o funcional y geográfica...Se trata de mecanismos que en su mayor parte tienen a alterar a 'la baja' la intensidad de los mecanismos de protección...". ${ }^{31}$

El movimiento de desregulación o flexibilización surgió en la mayoría de los países occidentales en las décadas de los setenta y ochenta. ${ }^{32}$

\section{Sus causas profundas se hallan en la crisis económica y la transformación tecnológica. ${ }^{33}$}

La crisis económica se asocia a la crisis del petróleo de 1973-1975 cuando se produjo una ruptura energética, industrial y monetaria ${ }^{34}$, que se prolongó en el tiempo, y tuvo como consecuencia el aumento del desempleo, marcando "el fin de una era- una 'onda larga', casi treinta años, de ciclo económico- caracterizada por un proceso de continuo crecimiento" al amparo del Estado de Bienestar. ${ }^{35}$

Culminaron los llamados "treinta años gloriosos", de éxito económico nunca conocido en la historia de la humanidad, donde las demandas sociales podían ser atendidas en razón de la capacidad distributiva emergente de la acumulación y en una época de pleno empleo donde las medidas de acción directa de los trabajadores podían generar grave perjuicio económico. ${ }^{36}$

La crisis aludida produjo que el poder político pasara a los partidos conservadores, o a los de centroizquierda que se corren hacia la derecha y aplican recetas parecidas, que los sectores empresariales tomaran la iniciativa sustituyendo el "impulso progresista movido por los obreros", y que los sindicatos se debilitaran. ${ }^{37}$

La transformación tecnológica, por su parte, contribuye a crear desocupación porque sustituye mano de obra por máquinas e "introduce en la realidad laboral un ingrediente dinámico, opuesto al quietismo y propicio al cambio". ${ }^{38}$

El derecho del trabajo clásico- que antes otorgaba seguridad en el mercado de trabajo, en

\footnotetext{
31 GOLDÍN Adrián, Conceptualización universal y construcciones locales sobre la idea del derecho del trabajo, DT, diciembre 2010, Año LXX, No12, p.3171. 32 SUPIOT, ob.cit., p. 195; CAPÓN FILAS, Rodolfo, Derecho del Trabajo. Análisis teórico y práctico del derecho de las relaciones individuales de trabajo. Sentido de la empresa y del trabajo en la Globalización, Librería Editorial Platense, La Plata, 1998, p.297; VÁZQUEZ VIALARD, Ayer, hoy y mañana en el derecho del trabajo, cit.

33 PLÁ RODRÍGUEZ, Américo, Un enfoque sobre la globalización, DT,1990-A,159; RIMOLDI, Alberto L., Reflexiones sobre la flexibilidad, DT1990-A,327; PODETTI, Humberto A., La flexibilidad en el Derecho del Trabajo: noción, aspectos y merituación, DT-1990-B,1319; FUENTES PUELMA, Carlos, "La flexibilidad normativa laboral y su relación con la pequeña y mediana empresa latinoamericana", rev. Relaciones Laborales y Seguridad Social, Año I,Nº, enero de 1996,p.1129

34 BIRGIN, Mauricio, Política de empleo e ingresos. ¿Qué es la flexibilidad laboral?, DT-1990-A,829.

35 BILLOUROU DE COMADIRA, Solange, La reforma laboral: ¿Profundización o revisión de 'tendencias flexibilizadoras’?,TySS-1999,151.

36 VÁZQUEZ VIALARD, Ayer, hoy y mañana en el derecho del trabajo, cit..

37 PLÁ RODRÍGUEZ, ob.cit.

38 Ídem nota anterior
} 
la renta, en el empleo y en el trabajo ${ }^{39}$ - no tenía respuestas para el "trabajo atípico" y para "los desocupados, ubicables en la zona del no derecho". ${ }^{40}$

Se advierte el protagonismo de las estrategias descentralizadores que rompen el paradigma clásico de la empresa; se vincula con los avances tecnológicos, aunque también actúan otros factores. La innovación tecnológica tiene carácter universal y celeridad. La empresa escueta (mezquina) también ahorra "mano de obra", debido al empleo masivo de trabajo subcontratado, lo que facilita un régimen de precariedad laboral que se traduce en temporalidad, trabajo a tiempo parcial y aún bajos salarios, fenómenos todos ellos que responden al proceso de descentralización productiva.

La descentralización productiva se ha traducido en degradación y deterioro de las condiciones de empleo. Es indudable que el proceso de descentralización productiva transformó el tejido social al facilitar la multiplicación de la cadena de empresas, en especial las de carácter auxiliar, como consecuencia de la externalización de funciones no estratégicas (que antes realizaban) por parte de las empresas centro (ex fábricas); ello hizo aumentar el número de las de pequeñas dimensiones, sujetas a un más alto índice de falencias. En la mayor parte de los países desarrollados o en vías de ese proceso, en los últimos 25 años, se ha reducido el personal de las grandes empresas, mientras que el de las Pyme experimentó un crecimiento, motivo por el cual se han creado nuevos empleos, en especial en el sector servicios, aunque con frecuencia de menor calidad del que tenían los que aquéllas prescindieron.

El proceso de descentralización productiva ha puesto en crisis algunos aspectos de la gran empresa, en especial los que se refieren a ella como organización de integración vertical y jerárquica (que el derecho del trabajo clásico tuvo como modelo); pero además funcionó como mecanismo de concentración del capital que diversifica y disloca geográficamente su actividad. Se pasa de la uniformidad a la fragmentación; de la estabilidad a la incertidumbre.

El Derecho del Trabajo, en su formación clásica, había excluido al trabajador autónomo. Su centro fue el dependiente, por lo que aquél fue desplazado de su ámbito propio. El proceso de descentralización operativa incrementó el número de trabajadores autónomos o, por lo menos, no dependientes. Se incrementó el número de los trabajadores que lo hacen en esas condiciones, pero también cambió el perfil del autónomo. Éste antes solía hacerlo en actividades propias de la industria artesanal, en el pequeño comercio, en el transporte de reducidas dimensiones, en los oficios tradicionales, en las profesiones liberales, etc., y solía serlo respecto de toda la vida laboral de sus titulares. ${ }^{41}$

En cambio ahora se presenta otra faz, en cuanto el trabajador que lo hace en esas condiciones suele alternar períodos de trabajo dependiente con el autónomo. Aparecen zonas grises entre dependencia y autonomía como son los trabajadores autónomos económicamente dependientes, parasubordinados o cuasi-asalariados.

\section{IV.- La nueva cuestión social}

Aparece en el último cuarto del siglo XX en adelante y se caracteriza por la creciente

39 BIRGIN, ob.cit.

40 LIVELLARA, ob.cit.

41 Ver "Los profesionales liberales" en DEVEALI, Mario L., Lineamientos de Derecho del Trabajo, TEA, Buenos Aires, 1948 , p. 335. 
pobreza estructural, el desempleo y la exclusión y el problema de la inseguridad. Los hiposuficientes pueden ser ahora otros distintos de los que antes vislumbramos como tales; o quizás más o quizás menos.

La segmentación del proceso productivo y la deslocalización de las empresas caracteriza a la actual globalización. ${ }^{42}$ Aparece fuertemente la preocupación medioambiental.

Estamos ante la sociedad postindustrial, las transformaciones derivadas de la era digital, un cambio del mundo analógico al digital. Asistimos a los efectos de la implantación de la Industria 4.0 desde la óptica de Derecho del Trabajo; se habla de Derecho del Trabajo 4.0.

Se expresa que "la Industria 4.0 consiste en incorporar las nuevas tecnologías a la industria. Dicho en otros términos, es hacer andar la industria a través de herramientas tecnológicas, tales como cloud, Big Data, sistemas ciber-físicos, sensórica, robótica colaborativa, fabricación aditiva o por capas, entre otras. Por tanto, es la considerada como la Cuarta Revolución Industrial, que se basa en la disponibilidad en tiempo real de toda la información relevante al producto, proporcionada por una red accesible en toda la cadena de valor, así como la capacidad para modificar el flujo de valor óptimo en cualquier momento. Esto se logra a través de la digitalización y la unión de todas las unidades productivas de una economía. Para ello es necesaria la fusión de tecnologías tales como Internet de las Cosas (IoT), computación y cloud, big data y ciberseguridad, así como las complementarias: móvil, analytics, M2M (Machine to Machine), impresión 3D, robótica y comunidad/compartición». La digitalización es la herramienta que diferencia a la Industria 4.0 con las demás, dados que combinan el aspecto físico con el digital. Como, por ejemplo, la vinculación de materiales, dispositivos, instalaciones, maquinarias al sistema digital. Se han dado voces al señalar que la digitalización une el puente que combina en el extremo a sociedad y tecnología que conecta con el otro extremo del mundo físico con el virtual. Entre los ejemplos de la activación de la digitalización en la industria se destacan, como ya se ha adelantado, entre otros, el internet, Big Data, impresoras 3D, robots, etiquetas RFID, teletrabajo, pagos remotos, nube de datos, colaboración en documentos compartidos, comunicación móvil, realidad aumentada, geolocalización, app, cloud computing, transformaciones derivadas de la era digital". ${ }^{43}$

El teletrabajo, con todas sus variedades, es una realidad. ${ }^{44}$

Sin embargo se mantiene la necesidad de la tutela o protección del más débil, que se da cuando no existe paridad negocial entre las dos partes que intercambian trabajo humano por dinero; el débil subordina su decisión al poder del fuerte quien lo convence manejando su potencial alimentario. El Derecho del Trabajo partió de una realidad: el trabajador es un hiposuficiente, principalmente por razones económicas, culturales o sociales frente al empleador y se halla- por eso mismo- en condiciones desventajosas para negociar. ${ }^{45}$ Esencialmente ello no se ha modificado.

\footnotetext{
42 SECO, Ricardo Francisco, "La globalización en la Doctrina Social de la Iglesia", en Sedes Sapientiae, Revista del Vicerrectorado de Formación de la Universidad Católica de Santa Fe, Año V, N 5, noviembre de 2002, p.295 a 309.

43 KAHALE CARRILLO, Djamil Tony, ponencia no oficial sobre "Los efectos de la implantación de la Industria 4.0 desde la óptica de Derecho del Trabajo", en XXII Congreso Mundial de Derecho del Trabajo y la Seguridad Social, SIDTySS-OIT, Turín, 2018

44 PIAZZA, Edder Hernán, "Nuevas relaciones del trabajo, teletrabajo y parasubordinación", exposición en el Instituto de Derecho del Trabajo y la Seguridad Social "P. Alberto Hurtado", de la UCC, 13/8/2012

45 SECO, Ricardo Francisco, "Las desigualdades compensatorias en el nuevo art.17 bis, LCT", en Revista de Derecho Laboral - Actualidad, 2010-2, Rubinzal Culzoni, Santa Fe, 2010, p.301/315.
} 


\section{V.-Crisis del Derecho del Trabajo}

Desde fines de los años ochenta se viene hablando de crisis del Derecho del Trabajo, específicamente de crisis de abarcatividad, desenfoque, de adaptabilidad, de fuga de sujetos.

Ésta es una de las cuestiones que más angustian a los estudiosos y operadores del Derecho del Trabajo.

Se advierte que "hay una mutación de los sujetos tradicionales del derecho del trabajo y la difuminación de la personalidad del empleador, a partir de un modo de ver el sistema normativo. Se registran casos judiciales de no aplicación de la legislación laboral, de incertidumbre en el ámbito de los diseños legislativos y de trabajo no enmarcados en el contrato de trabajo, pero en situación de dependencia económica. La flexibilidad laboral se propicia con alteraciones a la baja en la intensidad de la protección de los ordenamientos jurídicos, incluso con la flexicuridad europea, pero que no modifican la lógica tutelar". 46

La crisis económica ha sido históricamente compañera de viaje del derecho del trabajo. ${ }^{47}$ Él nació de la crisis del sistema capitalista del siglo XIX y ha habido, a lo largo de sus más de cien años de historia, muchas veces intenciones de borrarlo del todo o reducir su alcance.

La relación actual entre las fuentes del Derecho del Trabajo se modifica porque se debilita la ley frente al convenio colectivo y los convenios de actividad frente a los de empresa. ${ }^{48}$

Aparecen propuestas legislativas que se sancionan para la solución de estos problemas abarcando a trabajadores jurídicamente autónomos pero económicamente dependientes, o cuasi-asalariados o parasubordinados, como las contenidas en el Estatuto del Trabajador Autónomo español de 2007.49

Se dan las llamadas relaciones laborales atípicas pero que, finalmente, refieren a la tradicional locación de servicios. Hay nuevos retos que traen a la luz viejos debates.

A la preocupación acerca del futuro del Derecho del Trabajo se la han planteado políticos, legisladores, autores, etcétera.

Cosa diferente sucede con el Derecho Civil. Si bien es pasible de reformas, cambios en muchas de sus instituciones, pero nadie se plantea su futuro y menos su desaparición.

Se han registrado cambios en las variables que conforman el entorno económico y social del Derecho del Trabajo que quizás deberían también determinar una variación en el sistema jurídico normativo que regula el trabajo.

Se trata de "ubicar los retos del derecho del trabajo dentro del marco de los cambios que ha conocido el mundo en la última parte del siglo pasado y que se han acentuado al comenzar el presente siglo. Si el derecho del trabajo conoce una crisis profunda y ha

\footnotetext{
46 GOLDÍN, Adrián, "El futuro del Derecho del Trabajo (Un nuevo desafío para el Derecho y la equidad)", en AA.VV., Ensayos sobre El futuro del derecho del trabajo, Zavalía, Buenos Aires, 1997,p.59.

47 PALOMEQUE LÓPEZ, Manuel Carlos, "Un compañero de viaje histórico del Derecho del trabajo: la crisis económica”, en Revista de Política Social, 1984, n. 134

48 Ídem nota anterior.

49 AGUILAR MARTíN, María Carmen, El régimen jurídico del trabajador autónomo económicamente dependiente, Editorial Comares, Granada, 2015.
} 
sufrido cambios que se pueden calificar de traumáticos, es porque el mundo en el que vivimos se ha alejado mucho del paradigma de los Treinta Gloriosos dentro del que el Estado de Bienestar llegó a su máxima expresión, el pleno empleo era la norma, la sociedad era industrial, lo esencial del comercio internacional se hacía entre países que compartían valores similares y la economía de mercado también se pretendía social.

Considerábamos en aquella época que el Derecho del Trabajo cumplía una función que en lo político coadyuvaba a fortalecer la democracia y en lo económico y social buscaba consolidar la justicia distributiva, y esto tenía gran importancia en un mundo dividido entre dos sistemas políticos e ideológicos antagónicos. Imaginábamos también que la economía continuaría creciendo indefinidamente, que siempre habría empleos asegurados para todos los que deseaban trabajar y que los salarios sólo podrían aumentar. Así, nuestro razonamiento nos llevaba casi inevitablemente a la conclusión de que el derecho del trabajo estaba destinado a progresar de una manera por así decirlo geológica o por sedimentaciones sucesivas pues solamente se podía concebir un cambio de legislación laboral cuando su objeto era agregar nuevos derechos a los ya existentes, los que se suponían definitivamente adquiridos para los trabajadores y por eso mismo irrevocables." ${ }^{150}$

El Derecho del Trabajo "hoy conoce una fuerte crisis y está expuesto a embates que lo someten a ruda prueba. De allí a hablar del fin del derecho del trabajo hay un solo paso, y hoy no faltan quienes estén tentados a darlo." ${ }^{51}$

Mas las situaciones no son idénticas en todas las regiones del mundo.

La crisis del Derecho que nos ocupa es una consecuencia de la crisis actual de la sociedad capitalista. ${ }^{52}$

Este Derecho sufre cuatro tipos diferentes de crisis: de cobertura, de adaptación, de territorialidad y finalmente la ideológica. ${ }^{53}$

Un dato nuevo que se debe agregar es que en gran parte del mundo y a fines del siglo XX y comienzos del siglo XXI, en especial en Argentina, se despliega un modo de trabajo en la llamada economía popular, informal o autoempleados ${ }^{54}$, economía gris o negra. Éste ha merecido la consideración de la Organización Internacional del Trabajo ${ }^{55}$ y, por sus particularidades, quizás deba tener la consideración futura del Derecho del Trabajo.

\section{VI.-Ensayo una posible respuesta}

Algunos años atrás los reconocidos profesores Robert Castel y Adrián Goldín se preguntaban "si nos hallamos ante un redespliegue o ante una refundación del Derecho del Trabajo. Ese dilema, planteado como debate intelectual, sigue siendo, en mi opinión, plenamente vigente. ${ }^{56}$

\footnotetext{
50 BRONSTEIN, Arturo, Retos actuales al derecho del trabajo, DT-2005-B, 1367.

51 Ídem nota anterior.

52 ROMAGNOLI, Umberto, Introducción: El futuro del Derecho del Trabajo no será el que una vez fue, en https://revistas.upr.edu/index.php/ap/article/ viewFile/5178/4103, consultada el 25 de octubre de 2018.

53 BRONSTEIN, ob.cit.

54 XXII Congreso Mundial de Derecho del Trabajo y de la Seguridad Social, Turín 2018, Las transformaciones del trabajo: retos para los sistemas nacionales de legislación laboral y seguridad social, VILLASMIL PRIETO, Humberto, ponencia oficial: Informe mundial sobre trabajadores informales.

Ver también ARESE, Mauricio César, ponencia no oficial sobre el tema: Trabajadores informales, Contradicciones y confluencias entre trabajadores informales y formales.

55 Conferencia Internacional del Trabajo, Recomendación 204 sobre la transición de la economía informal a la economía formal, 104ª reunión, 12 de junio de 2015.

56 VILLASMIL PRIETO, ob.cit..
} 
Ante el interrogante de cuál será el futuro del Derecho del Trabajo no podemos hacer futurología.

Sólo nos atrevemos a decir que sabemos que ya no será el que fue. Deberá reinventarse. ${ }^{57}$ En él estará en la posible respuesta a esos retos, la solución a sus diversos tipos de crisis. Apostamos al mantenimiento de esta rama del derecho o a su modificación sin perder lo que lo identifica: su función de protección de los hiposuficientes, procurar que el trabajo humano no se convierta en una mercancía; que el derecho del trabajo no nos haga olvidar al derecho al trabajo.

Se debe pensar el futuro del Derecho del Trabajo pero sin olvidar las raíces. ${ }^{58}$

Quizás el nuevo Derecho del Trabajo admita que se abarque incluyendo diversos grados de protecciones: primero un núcleo duro de protección a un colectivo de trabajadores dependientes, registrados; luego un nivel intermedio de protección similar a los trabajadores autónomos económicamente dependientes y, más tarde, el amplio mundo de los trabajadores informales. ${ }^{59}$

A pesar de todo, no se altera la idea básica del Derecho del Trabajo: "la autonomía individual sigue enmarcada por un aparato normativo tendiente a neutralizar la sustancial asimetría de la autonomía individual. ${ }^{60}$ Se busca una igualdad formal y sustancial real.

Los valores inspiradores del futuro del trabajo y del Derecho del Trabajo en Argentina se encuentran en el bloque de constitucionalidad federal(Constitución Nacional y tratados sobre derechos humanos del art.75 inc.22 de la CN); pero también en la Declaración OIT relativa a los principios y derechos fundamentales en el trabajo, del 18 de junio de 1998, anexo revisado el 15 de junio de 2010, como en la Declaración de la OIT sobre la justicia social para una globalización equitativa del 10 de junio de 2008, con lo cual hay un empoderamiento de las normas internacionales del trabajo.

Lo mismo sucede con el trabajo decente, "un paradigma positivo o un criterio práctico, que sirve para enjuiciar o valorar éticamente cualquier clase de trabajo", "un paradigma ético".61

En todo caso sigue vigente el principio expuesto por el Magisterio Social de la Iglesia Católica desde 1891 y por la Constitución de la OIT de que "el trabajo humano no constituye una mercancía"62, base también del Derecho del Trabajo y motivo para la existencia de

57 ROMAGNOLI, ob.cit.

58 LASTRA LASTRA, José Manuel, El futuro del Derecho del Trabajo, en https://archivos.juridicas.unam.mx/www/bjv/libros/1/99/12.pdf, consultado el 25 de octubre de 2018.

59 ARESE, ob.cit.; VILLASMIL PRIETO, ob.cit.

60 GOLDÍN, ob.cit..

61 BAYLOS GRAU, Antonio, El futuro de las normas del trabajo que queremos, en https://www.ilo.org/wcmsp5/groups/public/---europe/---ro-geneva/--ilo-madrid/documents/article/wcms_548608.pdf, consultada el 25 de octubre de 2018. Ver Memoria del Director General de la Organización Internacional del Trabajo en su $87^{\text {a }}$ Reunión, en 1999, donde aparece el término "trabajo decente".

62 MEJÍA, Jorge, La cuestión social, Paulinas-Criterio, Buenos Aires, 1998, p.134, expresa que "la enseñanza magisterial sobre el trabajo desde su inicio puede formularse así: 'el trabajo no es una mercancía. No se vende ni se puede comprar. Es un derecho y como tal debe ser respetado como deben ser respetadas sus exigencias intrínsecas. Ni el patrón ni el obrero ni el contexto social pueden lícitamente obrar o dejar de obrar como si la capacidad de trabajo de cada individuo, o de muchos, fuese un bien libremente negociable, vendido al mejor postor. Esto constituye, objetivamente, una injusticia."

Ver Declaración relativa a los fines y objetivos de la Organización Internacional del Trabajo (Declaración de Filadelfia) adoptada el 10 de mayo de 1944 en https://www.ilo.org/legacy/spanish/inwork/cb-policy-guide/declaraciondefiladelfia1944.pdf, consultada el 25 de octubre de 2018. Ver Corte Suprema de Justicia de la Nación, 14/9/2004, "Vizzoti, Carlos Alberto c/ AMSA S.A. s/Despido",21/9/2004, y "Aquino, Isacio c/Cargo Servicios Industriales S.A." RDL, Número Extraordinario, Fallos recientes de la Corte Suprema de Justicia de la Nación, Santa Fe, Rubinzal Culzoni, 2004 , ps.12 y 77 respectivamente. 
una rama del derecho que procura el logro del "trabajo digno", que es aquél que "respeta los derechos fundamentales de la persona humana, así como los derechos de los trabajadores. ${ }^{63}$

Mientras haya necesidad de protección de los hiposuficientes que trabajan será menester la existencia de un Derecho como el que cultivamos aunque tenga otros matices. 